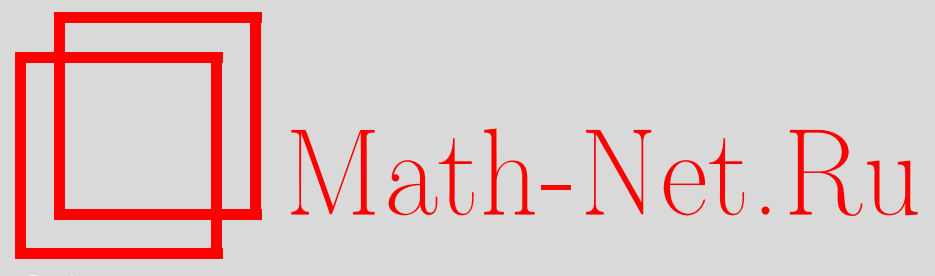

Т. Б. Минасов, А. Л. Матвеев, А. В. Нехожин, Прочностные характеристики проксимального отдела бедренной кости в условиях внутреннего силового шунтирования, Вестн. Сам. гос. техн. унта. Сер. Физ.-мат. науки, 2013, выпуск 4(), 98-106

DOI: https://doi.org/10.14498/vsgtu1270

Использование Общероссийского математического портала MathNet.Ru подразумевает, что вы прочитали и согласны с пользовательским соглашением

http: //www . mathnet.ru/rus/agreement

Параметры загрузки:

IP: 52.6 .47 .48

26 апреля 2023 г., 15:59:53

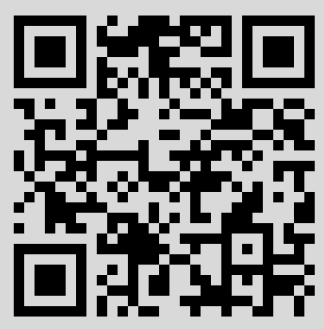


Вестн. Сам. гос. техн. ун-та. Сер. Физ.-мат. науки. 2013. № 4 (33). С. 98-106

\title{
Биомеханика
}

УДК 539.41

\section{ПРОЧНОСТНЫЕ ХАРАКТЕРИСТИКИ ПРОКСИМАЛЬНОГО ОТДЕЛА БЕДРЕННОЙ КОСТИ В УСЛОВИЯХ ВНУТРЕННЕГО СИЛОВОГО ШУНТИРОВАНИЯ}

\author{
Т. Б. Минасов ${ }^{1}$, А. Л. Матвеев $^{2}$, А. В. Нехожин \\ 1 Башкирский государственный медицинский университет, \\ 450000, Уфа, ул. Ленина, 3. \\ 2 Центральная городская больница, \\ 446200, Самарская обл., Новокуйбышевск, ул. Пирогова, 1. \\ 3 Самарский государственный технический университет, \\ Россия, 443100, Самара, ул. Молодогвардейская, 244. \\ E-mails: m004@yandex.ru, mal57@rambler.ru, stswoon@yandex.ru
}

\begin{abstract}
Описывается метод хирургического профилактического армирования проксимального отдела бедренной кости у лии, пожилого возраста, страдающих различными заболеваниями, которые вызывают дистрофические и диспластические прочессы в костной ткани (онкология, остеопороз, фиброзная и хрящевая дисплазия и др.) и, как следствие, являются причиной патологических переломов. Оригинальные армирующие имплантаты (патенты РФ № 91845, 98901, 101351, 121725) устанавливаются в интактную кость проксимального отдела бедра с иелью предупреждения её переломов при низкоэнергетической травме, что способствует повышению прочности костной ткани. Методика пробилактического армирования имеет математическое и экономическое обоснование. Повышение прочности проксимального отдела бедра, армированного имплантатами из наноструктурированного титана, доказано стендовыми испытаниямu.
\end{abstract}

Ключевые слова: проксимальный отдел бедра, профилактическое армирование, имплантаты, математическое моделирование, прочность.

Введение. Демографические процессы, происходящие в современном обществе, приводят к резкому увеличению в популяции лиц пожилого и старческого возраста ортопедического профиля во всех развитых государствах $[1,2]$. Способность пожилого человека вести независимую жизнь - важная составляющая, обеспечивающая физический компонент качества жизни. Метаболические заболевания опорно-двигательной системы являются значимым фактором риска малоэнергетических повреждений крупных сегментов скелета $[3,4]$. Остеопорозные переломы позвонков и пояса верхних конечностей приводят к хроническому болевому синдрому, однако наиболее фатальными являются переломы в области проксимального отдела бедренной кости, так как сопряжены с высокой летальностью [5]. В некоторых регионах Россий-

Тимур Булатович Минасов (к.м.н.), доцент, кафедра травматологии и ортопедии с курсом ИПО. Анатолий Львович Матвеев (к.м.н.), врач-ординатор, травматологическое отделение. Анатолий Вадимович Нехожин, аспирант, кафедра прикладной математики и информатики. 
ской Федерации летальность после перелома проксимального отдела бедра достигает от 45 до $52 \%$.

Всемирная организация здравоохранения в 2006 году выдвинула остеопороз на третье место по смертности после заболеваний сердечно-сосудистой системы и злокачественных новообразований. По данным национальной ассоциации статистики здоровья (2005 г.), на территории США ежегодно происходит 1,5 млн переломов, связанных с остеопорозом, из них 700 тыс. переломов позвоночника, 250 тыс. переломов шейки бедра, 250 тыс. переломов дистального отдела лучевой кости и 300 тыс. переломов в других областях скелета. При этом предполагается, что количество остеопорозных переломов в мире с 1,7 млн в 1990 году увеличится до 6,3 млн в 2050 году, т. е. возрастёт примерно в четыре раза.

Несмотря на фундаментальные открытия в области молекулярной биологии, медикаментозное лечение системного остеопороза сопряжено с необходимостью длительного приёма препаратов и низкой приверженностью к подобного рода терапии, что не позволяет обеспечить клинически значимого снижения риска переломов у достаточно большого массива пациентов. Из механики деформируемого твёрдого тела известно, что на прочность сегмента костной ткани влияют такие свойства среды, как упругость, пластичность и вязкоупругость [6-9]. Одним из альтернативных решений оптимизации упругих и прочностных свойств проксимального отдела бедренной кости является методика превентивного хирургического армирования, позволяющая эффективно снизить риск переломов рассматриваемой локализации [10].

Целью исследования послужило изучение механических характеристик биокомпозитной системы «кость - имплантат» в условиях профилактического остеосинтеза шейки бедренной кости.

1. Материал и методы исследования. В качестве исходного материала для имплантатов взят технический титан в наноструктурированном состоянии. Такое структурное состояние позволяет формировать качественно новые эксплуатационные свойства, выраженные в высоком уровне предела прочности - до 1300 МПа. Исходный диаметр прутков для изготовления армирующих элементов составлял 3 мм. Такие исходные данные позволили создать ряд перспективных имплантатов нового поколения с повышенной удельной прочностью и минимизированными геометрическими параметрами.

Изучению были подвергнуты 5 групп макетов бедренной кости в условиях остеосинтеза с различными типами оригинальных имплантатов; сравнение производилось с интактными (неармированными) образцами.

Исследуемые механические системы подвергались дозированной нагрузке по оси конечности, а также перпендикулярно оси бедренной кости с силой $P$, направленной на область большого вертела, до полного разрушения со скоростью 5 мм/мин на универсальном динамометре INSTRON 5982 (см. рис. 1).

В результате проведённого исследования выявлено, что разрушение интактных образцов при нагрузке по оси бедра (см. табл., рис. 2-4) в большинстве случаев происходило в области шейки при средней нагрузке 1,35 \pm 0,15 КН на 361 сек. эксперимента. Системы, фиксированные спицей, разрушались в подвертельной зоне при средней нагрузке 1,65 $\pm 0,15 \mathrm{KH}$ на 386 сек. эксперимента, что на 22,7\% дольше по сравнению с интактными образцами. Системы, фиксированные тремя спицами, также разрушались в подвертельной 


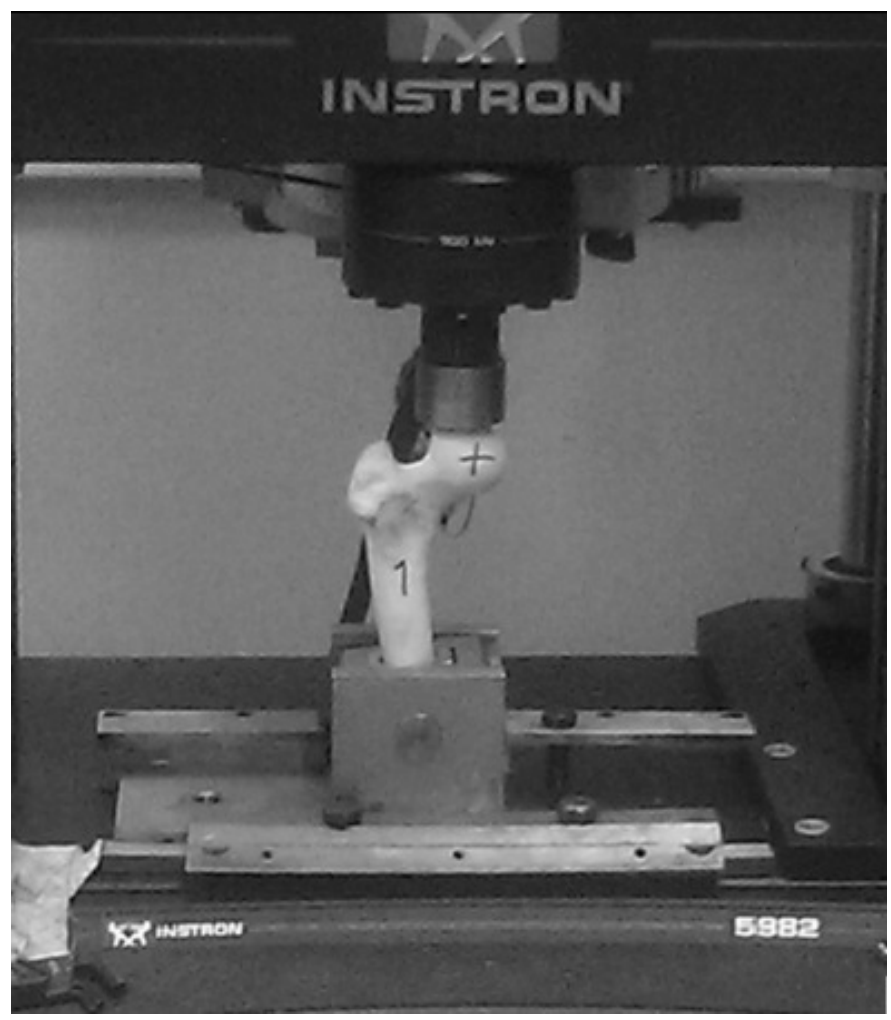

Рис. 1. Расположение механической системы в динамометре INSTRON 5982

Продолжительность упругого деформирования $t$ и начало разрушения $\boldsymbol{t}^{*}$ систем при сжатии максимальной нагрузкой $\boldsymbol{P}$

\begin{tabular}{|c|c|c|c|}
\hline Системы & $P, \mathrm{KH}$ & $t$, сек & $t^{*}$, сек \\
\hline \multicolumn{4}{|c|}{ Сжатие вдоль механической оси бедренной кости } \\
\hline Интактный образец & $1,35 \pm 0,15$ & 346 & 361 \\
\hline Спица & $1,65 \pm 0,15$ & 362 & 386 \\
\hline Перекрещивающиеся спицы & $1,89 \pm 0,15$ & 391 & 463 \\
\hline Винт-штопор & $2,10 \pm 0,15$ & 198 & 561 \\
\hline «Винт-штопор + спица» & $2,32 \pm 0,15$ & 243 & 532 \\
\hline \multicolumn{4}{|c|}{ Сжатие вдоль оси шейки бедренной кости } \\
\hline Интактный образец & $2,17 \pm 0,15$ & 231 & 331 \\
\hline Спица & $2,77 \pm 0,15$ & 336 & 385 \\
\hline Перекрещивающиеся спицы & $3,31 \pm 0,15$ & 359 & 410 \\
\hline Винт-штопор & $4,21 \pm 0,15$ & 338 & 361 \\
\hline
\end{tabular}




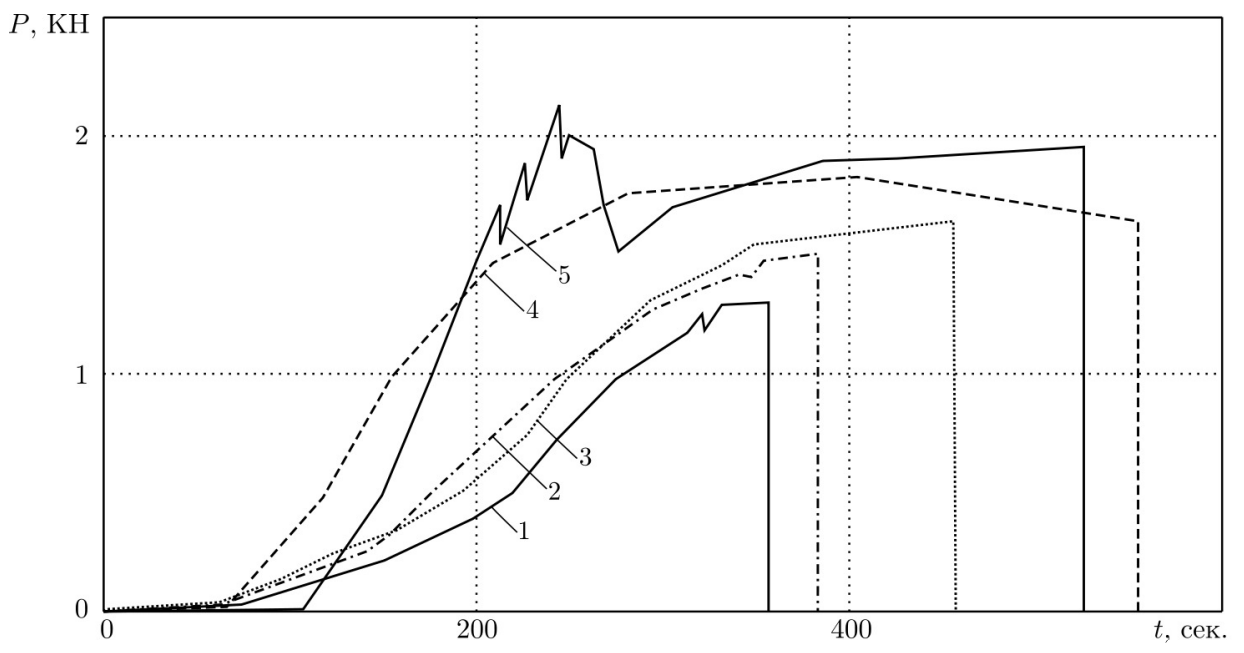

Рис. 2. Диаграмма деформирования «нагрузка - время» при сжатии вдоль механической оси бедренной кости: 1 - интактная кость; 2-5-имплантаты: спица (2), перекрещивающиеся спицы (3), винт-штопор (4), «винт-штопор + спица» (5)

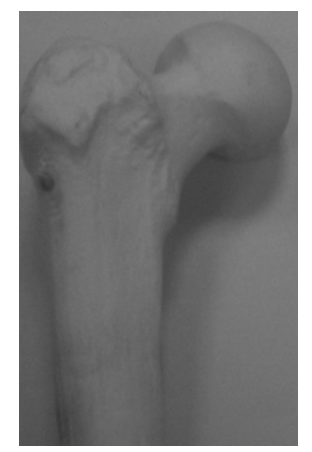

a1

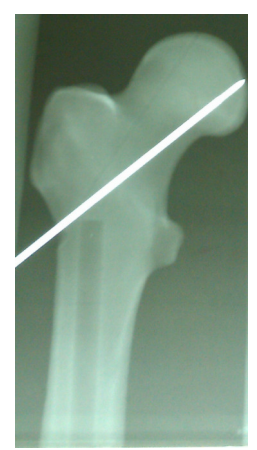

61

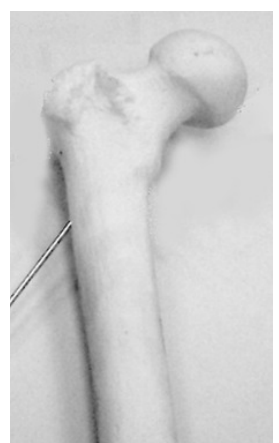

62

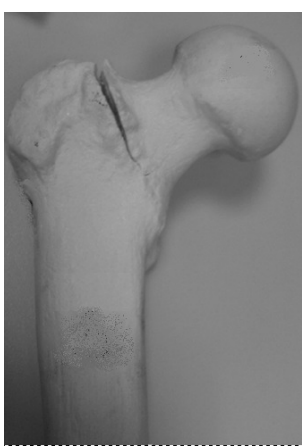

a2

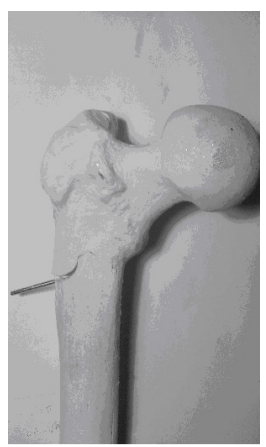

63

Рис. 3. Рентгенограммы и результаты испытаний: а1 - система интактного образца; а2 система интактного образца после разрушения; б1 - рентгенограмма образца со спицей; б2 система образца со спицей; 63 - система со спицей после разрушения 


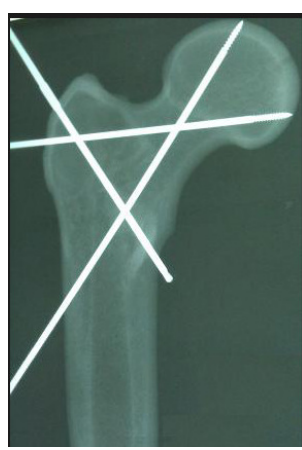

B1

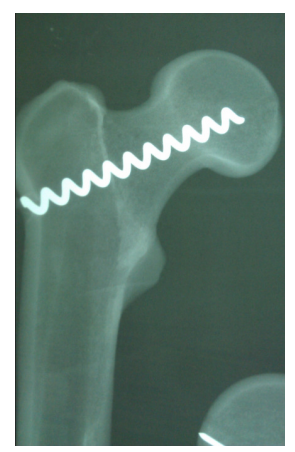

$\Gamma 1$

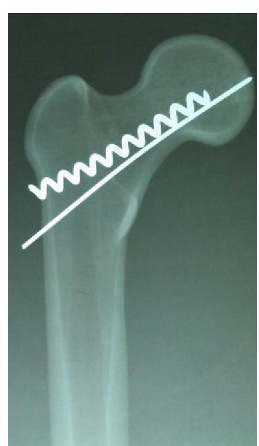

д1

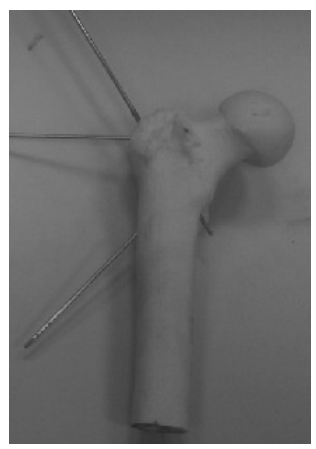

B2

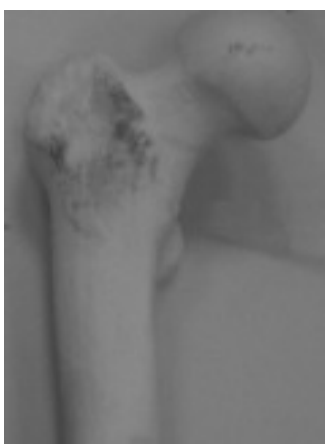

$\Gamma 2$

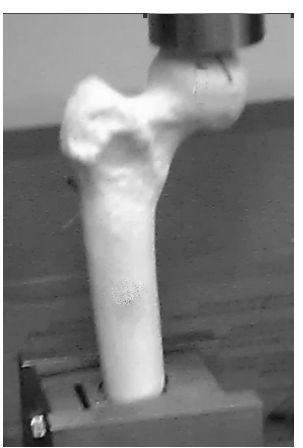

д2

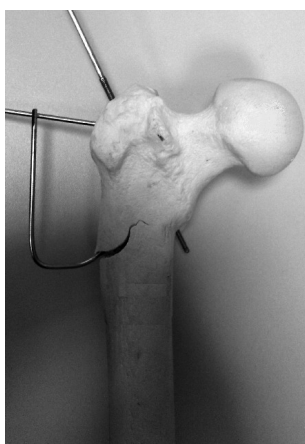

B3

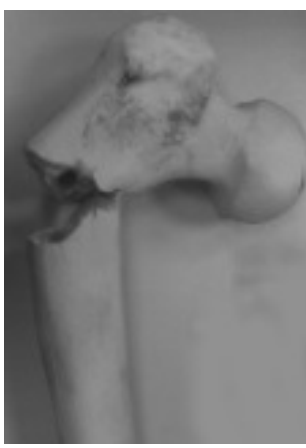

$\Gamma 3$

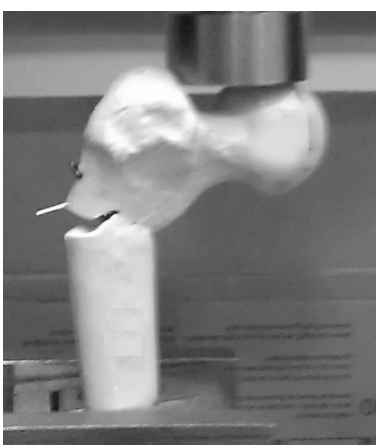

д3

Рис. 4. Рентгенограммы и результаты испытаний: в1-рентгенограмма системы с перекрещивающимися спицами; в2 - система с перекрещивающимися спицами; в3 - система с перекрещивающимися спицами после разрушения; $\Gamma 1$ - рентгенограмма системы с имлантатом винт-штопор; г2- система с имлантатом винт-штопор; г3 - система с имлантатом винт-штопор после разрушения; д1-рентгенограмма образца с имплантатом «винт-штопор + спица»; д2 - система «винтштопор + спица»; д3-система «винт-штопор + спица» после разрушения 
зоне, при этом теряли устойчивость при нагрузке 1,89 \pm 0,15 KН на 463 сек., прочность образцов превосходила интактные в среднем на 40,1\%. Системы, фиксированные винтом-штопором, разрушались при нагрузке $2,10 \pm 0,15 \mathrm{KH}$, в то же время продемонстрировали наибольшую временную резистентность, так как теряли устойчивость лишь на 561 сек. эксперимента. Прочность систем, фиксированных винтом, была выше на 56,1 \% по сравнению с интактными. Наиболее прочными из всех систем «кость - имплант» при осевом сжатии были образцы, фиксированные по схеме «винт-штопор + спица», которые сохраняли структурную состоятельность при нагрузках менее 2,32 \pm 0,15 KH, сопротивляемость осевой нагрузке была на 72,6\% выше интактных образцов, при этом было отмечено падение нагрузок до значений, сопоставимых с резистентностью систем, фиксированных винтами, с разрушением систем на 532 сек. эксперимента.

При сжатии аналогичных систем по оси шейки бедренной кости (см. табл., рис. 5, 6) в большинстве случаев отмечено разрушение области шейки бедренной кости в области перехода медиальной кортикальной пластины (дуги Адамса) в межвертельную линию. Так, интактный образец терял структурную состоятельность при средней нагрузке 2,17 \pm 0,15 KН на 331 сек. эксперимента. Системы, фиксированные спицей, разрушались при нагрузке $2,77 \pm 0,15 \mathrm{KH}$ на 385 сек., при этом прочность систем была выше интактных образцов в среднем на 27,9\%. Изученные образцы, фиксированные перекрещивающимися спицами, были на 52,6\% прочнее интактных, так как разрушались при средней нагрузке $3,31 \pm 0,15$ KН на 410 сек. эксперимента. Наиболее прочными из изученных при сжатии по оси шейки были системы, фиксированные по схеме винт-штопор, так как оставались устойчивыми при нагрузках менее 4,21 $\pm 0,15 \mathrm{KH}$ до 361 сек. эксперимента.

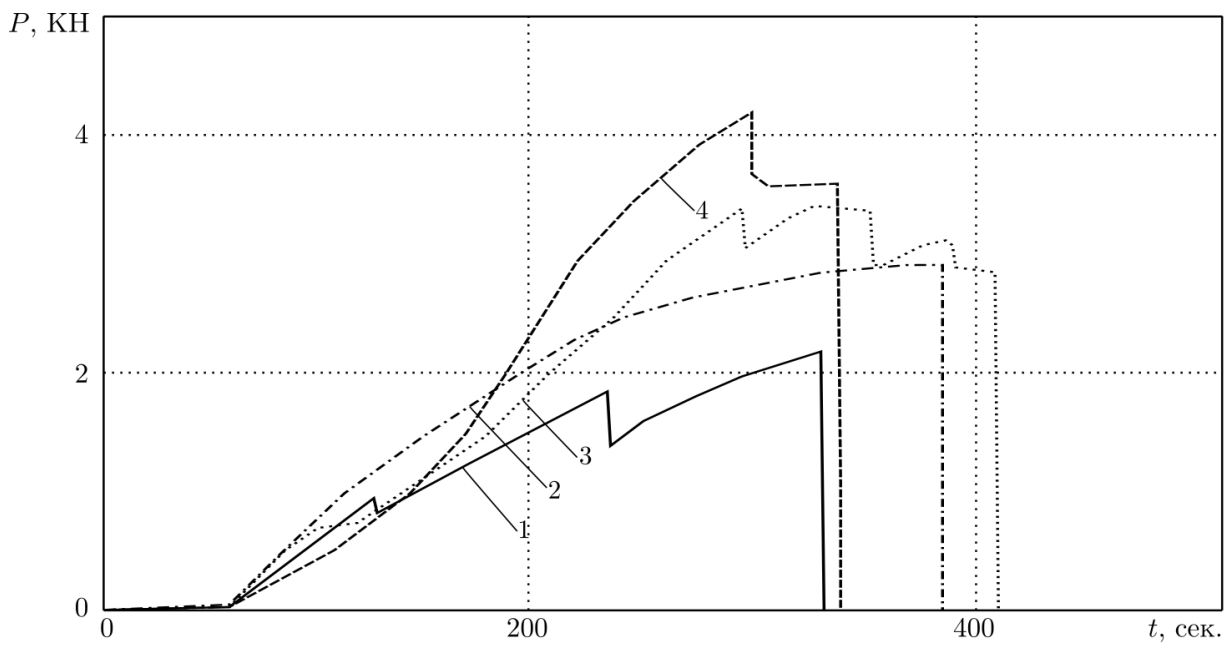

Рис. 5. Диаграмма деформирования «нагрузка - время» при сжатии вдоль оси шейки бедренной кости: 1 - интактная кость; 2-4-имплантаты: спица (2), перекрещивающиеся спицы (3), винт-штопор (4)

2. Обсуждение. Особенностью систем, фиксированных спицами, при сжатии вдоль механической оси бедренной кости (вне зависимости от компоновки имплантов) было разрушение образцов в подвертельной зоне непосредствен- 


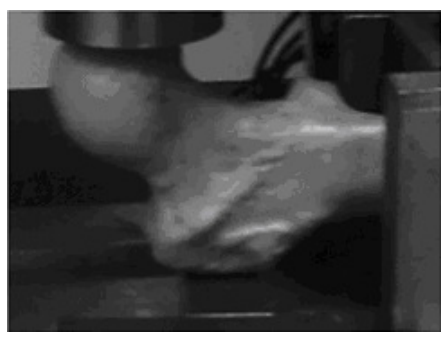

a1

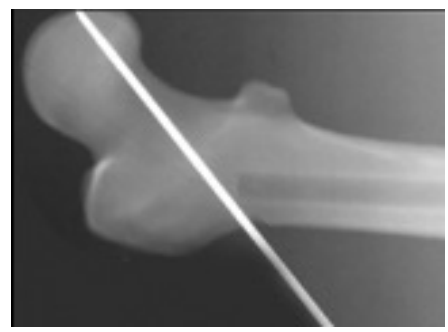

61

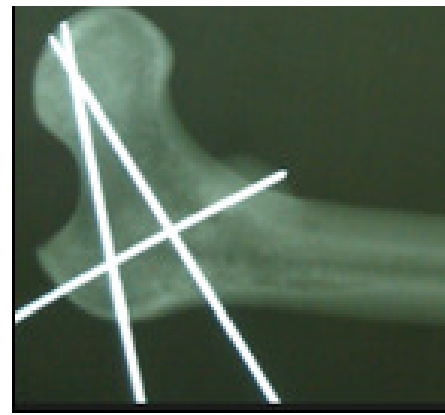

B1

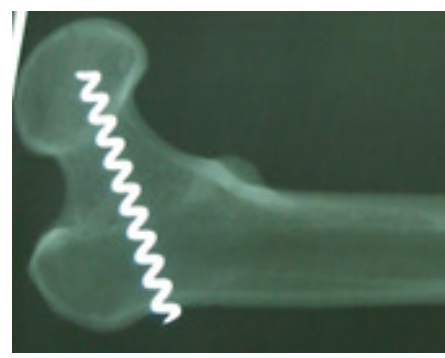

$\Gamma 1$

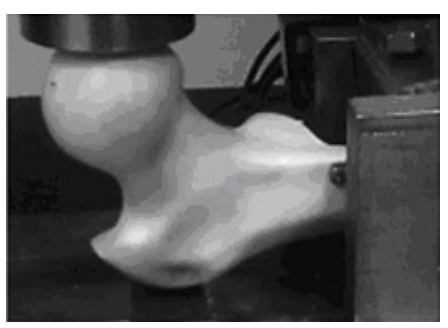

62

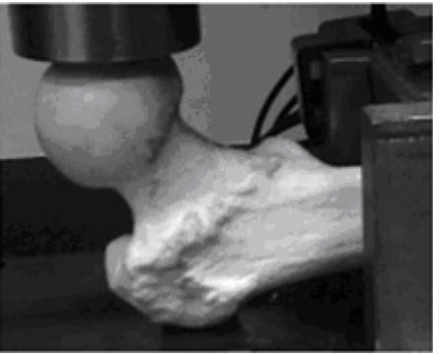

B2

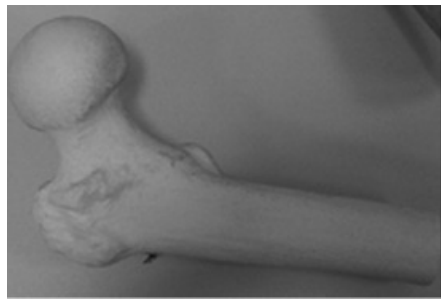

$\Gamma 2$

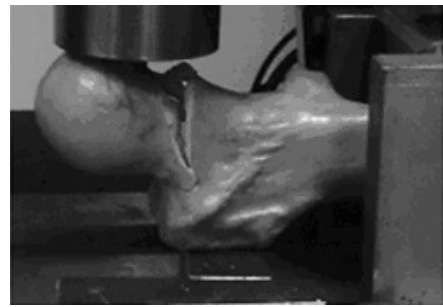

a2

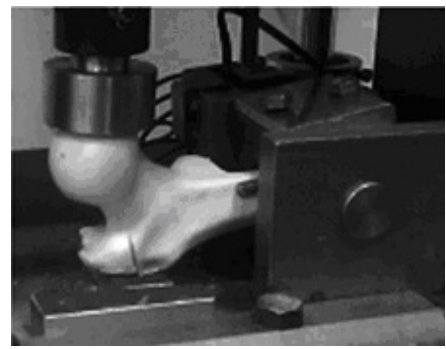

63

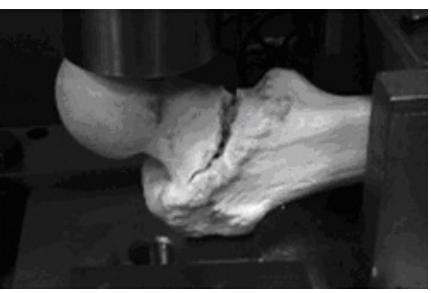

B3

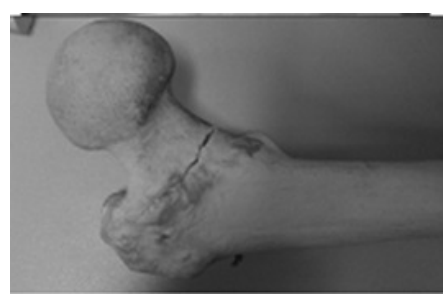

$\Gamma 3$

Рис. 6. Рентгенограммы и результаты испытаний: а1 - система интактного образца; а2 система интактного образца после разрушения; 61 - рентгенограмма образца со спицей; 62 - система образца со спицей; 63 - система образца со спицей после разрушения; в1 рентгенограмма системы с перекрещивающимися спицами; в2 - система с перекрещивающимися спицами; в3 - система с перекрещивающимися спицами после разрушения; г1 рентгенограмма образца с имплантатом винт-штопор; г2-образец с имплантатом винтштопор; г3 - образец с имплантатом винт-штопор после разрушения 
но под спицей, что, несомненно, свидетельствует о феномене «шунтирования» нагрузок.

Данные, полученные при анализе сопротивляемости осевой нагрузке, подтверждают преимущества систем, фиксированных винтами либо их комбинациями со спицами, что, по всей видимости, связано с большей площадью контакта в системах «кость - имплант», при этом прочность увеличивалась от 22 до $70 \%$.

Результаты, полученные при анализе устойчивости синтезированных систем при сжатии по оси шейки, также свидетельствуют о преимуществах систем с наибольшей площадью контакта, при этом сопротивляемость нагрузкам увеличивается от 27 до $93 \%$.

Другой особенностью изученных систем было то, что при нагрузках, приводящих к структурной деформации, их разрушение (в отличии от интактных образцов) происходило не полностью, а, как правило, монокортикально, что не приводило к дальнейшему смещению отломков.

Кроме этого, было отмечено наличие феномена «шунтирования» силовых линий и разрушение систем в периимплантной зоне, что, несомненно, требует дальнейшего изучения.

3. Выводы. Таким образом, все изученные способы фиксации увеличивают прочность системы «кость - имплант» при сжатии как по оси, так и вдоль шейки бедренной кости. При широком внедрении в клиническую практику методики профилактического армирования кости при различных процессах охрупчивания костной ткани проксимального отдела бедра у лиц, склонных к переломам, можно избавить их от вероятного перелома бедренной кости и тем самым продлить им жизнь.

\section{БИБЛИОГРАФИЧЕСКИЙ СПИСОК}

1. J. A. Kanis, N. Burlet, C. Cooper, P. D. Delmas, J.-Y. Reginster, F. Borgstrom, R. Rizzoli, "European guidance for the diagnosis and management of osteoporosis in postmenopausal women" // Osteoporos. Int., 2008. Vol. 19, no. 4. Pp. 339-428.

2. H. E. Meyer, G. K. Berntsen, A. J. Søgaard, A. Langhammer, B. Schei, V. Fønnebø, S. Forsmo, G. S. Tell, "Higher bone mineral density in rural compared with urban dwellers: the NOREPOS study" // Am. J. Epidemiol., 2004. Vol.160, no. 11. Pp. 1039-1046.

3. B. Shea, G. Wells, A. Cranney, N. Zytaruk, V. Robinson, L. Griffith, C. Hamel, Z. Ortiz, J. Peterson, J. Adachi, P. Tugwell, G. Guyatt, "Calcium supplementation on bone loss in postmenopausal women" // Cochrane Database Syst. Rev., 2004. no. 1, CD004526; Cochrane Database Syst. Rev., 2007. no. 1, CD004526.

4. A. Tenenhouse, L. Joseph, N. Kreiger, S. Poliquin, T. M. Murray, L. Blondeau, C. Berger, D. A. Hanley, J. C. Prior, "Estimation of the prevalence of low bone density in Canadian women and men using a population-specific DXA reference standard: the Canadian Multicentre Osteoporosis Study (CaMos)" // Osteoporos. Int., 2000. Vol. 11, no. 10. Pp. 897904.

5. Т. Б. Минасов, Б. Ш. Минасов, "Эффективность комбинированной терапии постменопаузального остеопороза с использованием препаратов двойного действия" // Травматология и ортопедия России, 2011. №4(62). C. 92-94. [T. B. Minasov, B. Sh. Minasov, "The effectiveness of combined therapy of postmenopausal osteoporosis with dual action drugs" // Travmatologiya Ortopediya Rossii, 2011. no.4(62). Pp. 92-94].

6. И. В. Кнетс, Ю. К. Вилкс, "Ползучесть компактной костной ткани человека при растяжении" // Мех. полим., 1975. № 4. С. 634-638; англ. пер.: I. V. Knets, Yu. K. Vilks, "Creep of compact human bony tissue under tension" // Polymer Mechanics, 1975. Vol.11, no. 4. Pp. 543-547. 
7. В. П. Радченко, Д. В. Шапиевский, "Математическая модель ползучести микронеоднородного нелинейно-упругого материала" // ПМТФ, 2008. Т. 49, № 3. С. 157-163; англ. пер.: V. P. Radchenko, D. V. Shapievskii, "Mathematical model of creep for a microinhomogeneous nonlinearly elastic material"// J. Appl. Mech. Tech. Phys., 2008. Vol. 49, no. 3. Pp. 478-483.

8. Х. Вини, "Изменение механических свойств компактной костной ткани человека в зависимости от возраста" // Mex. полим., 1975. №11. С. 659-663; англ. пер.: H. Vinz, "Change in the mechanical properties of human compact bone tissue upon aging" // Polymer Mechanics, 1975. Vol. 11, no. 4. Pp. 568-571.

9. М. А. Добелис, "Деформированые свойства деминералиованной костной ткани человека при растяжении"// Mex. полим., 1978. №1. С. 101-108; англ. пер.: M. A. Dobelis, "Deformation properties of demineralized human compact bone tissue upon stretching" // Polymer Mechanics, 1978. Vol. 14, no. 1. Pp. 85-91.

10. А. Л. Матвеев, Устройство для армирования шейки бедренной кости и превентивной профилактики её переломов: Патент РФ на полезную модель № 101351 от 20.01.2011. [A. L. Matveev, Device for reinforcement of the femoral neck and proactive prevention of their fracture: Utility model patents of the Russian Federation. No. 101351 of January 20, 2011].

Поступила в редакцию $01 / \mathrm{X} / 2013$;

в окончательном варианте - 01/XI/2013.

MSC: 74L15; 74-05

\title{
STRENGTH CHARACTERISTICS OF THE PROXIMAL FEMUR IN CONDITIONS OF INTERNAL FORCE SHUNTING
}

\author{
T. B. Minasov ${ }^{1}$, A. L. Matveev ${ }^{2}, A$. V. Nekhozhin ${ }^{3}$
}

1 Bashkir State Medical University, 3, Lenin str., Ufa, 450000

2 Central City Hospital,

1, Pirogov st., Novokuybyshevsk, Samara Region, 446200, Russia.

3 Samara State Technical University,

244, Molodogvardeyskaya st., Samara, 443100, Russia.

E-mails: m004@yandex.ru, mal57@rambler.ru, stswoon@yandex.ru

The present research describes a method of surgical prophylactic reinforcement of the proximal femur in elderly patients suffering from various diseases that cause degenerative and dysplastic processes in bone (oncology, osteoporosis, cartilage and fibrous dysplasia, etc). These processes cause pathological fractures. Original reinforcement implants (Russian Federation patents number 91845, 98901, 101351, 121725) are installed in the intact bone of the proximal femur to prevent its fractures in case of low-energy trauma, thereby increasing bone strength. Preventive reinforcement technique has a mathematical and economic feasibility. Increasing of the strength of the proximal femur, reinforced by implants from nanostructured titanium, is proved by bench tests.

Keywords: proximal part of the femur, prophylactic reinforcement, implants, mathematical modeling, strength.

Original article submitted $01 / \mathrm{X} / 2013$; revision submitted 01/XI/2013.

Timur B. Minasov (Ph. D. Medical), Associate Professor, Dept. of Traumatology and Orthopedics. Anatoliy L. Matveev (Ph. D. Medical), Physician-Ordinator, Casualty Department. Anatoliy V. Nekhozhin, Postgraduate Student, Dept. of Applied Mathematics \& Computer Science. 